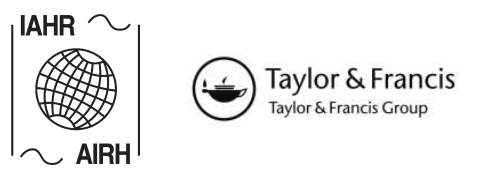

Journal of Hydraulic Research Vol. 48, No. 2 (2010), pp. 161-168

doi:10.1080/00221681003704129

(C) 2010 International Association for Hydro-Environment Engineering and Research

Research paper

\title{
Semi-empirical model for channel bed evolution due to lateral discharge withdrawal
}

\author{
BURKHARD ROSIER, Laboratory of Hydraulic Constructions (LCH), Ecole Polytechnique Fédérale de Lausanne \\ (EPFL), Station 18, 1015 Lausanne, Switzerland. Now at: Fichtner GmbH \& Co. KG, Engineering and Consulting - \\ worldwide, Sarweystraße 3, 70191, Stuttgart, Germany. \\ Email: burkhard.rosier@fichtner.de (author for correspondence)
}

JEAN-LOUIS BOILLAT, Laboratory of Hydraulic Constructions (LCH), Ecole Polytechnique Fédérale de Lausanne (EPFL), Station 18, 1015, Lausanne, Switzerland.

Email: jean-louis.boillat@epfl.ch

ANTON J. SCHLEISS (IAHR Member), Laboratory of Hydraulic Constructions (LCH), Ecole Polytechnique

Fédérale de Lausanne (EPFL), Station 18, 1015, Lausanne, Switzerland.

Email: anton.schleiss@epfl.ch

\begin{abstract}
Side weirs and overtopable levees are widely used to increase flood routing along a channel or river. The lateral loss of water reduces the sediment transport capacity leading to the formation of a local sediment deposit close to the overflow. Since the extent of the morphological bed changes is not known a priori, the design discharge is increased by this flow-sediment transport interaction in an uncontrolled way. Based on a systematic flume study, a semi-empirical model to predict the three-dimensional bed evolution of the aggraded channel reach in the vicinity of the overflow is developed. The shape of the deposit is modelled by an adapted Maxwell-type distribution function. The main input parameters of the model are expressed in terms of dimensionless parameters accounting for main channel and side overflow geometry as well as flow and sediment transport characteristics. The application of the empirical model in numerical flow calculations predicts $90 \%$ of the measured overflow.
\end{abstract}

Keywords: Bed morphology, deposition, sediment transport, semi-empirical model, side overflow, side weir

\section{Introduction}

Side overflows such as side weirs, fuse plugs or overtopping dams are free overflow regulation and diversion structures commonly encountered in river training works. The flow over a side weir is a typical case of spatially varied flow with decreasing discharge and has been subject to numerous investigations (e.g. Subramanya and Awasthy 1972, Hager 1987). Usually, the main design objective is to estimate the total overflow discharge. Therefore, this research focused on the determination of an appropriate discharge coefficient. Normally, a fixed channel bottom is assumed, since most studies refer to irrigation or drainage engineering (e.g. Borghei et al. 1999). Natural rivers have a mobile bed and the morphological behaviour has to be taken into account if dealing with flood protection projects.

The lateral water loss reduces the sediment transport capacity in the main channel due to decreasing bottom shear stress. This results in sediment deposition and a rise of the mean bed level as well as the formation of a local sediment deposit in the weir alignment. Consequently, the flow section is reduced, the upstream water level rises as does the head on the side weir. Hence, the design discharge is increased in an unforeseen way.

To obtain a better insight in the interaction of a side overflow with bed-load transport and bed morphology, systematic flume tests were performed (Rosier 2007b). These allowed a design procedure for the flow-sediment interaction consisting of a threedimensional (3D) semi-empirical approach predicting the bed evolution near the overflow to be developed. A twodimensional (2D) model and a method for direct estimation of the overflow have been developed as well (Rosier 2009b). The shape of the aggraded channel reach was modelled using a Maxwellian distribution function. The height and location of the maximum bed elevation and a shape factor are expressed in terms of dimensionless channel geometry, side weir variables,

$\overline{\text { Revision received } 11}$ November 2009/Open for discussion until 31 October 2010

ISSN 0022-1686 print/ISSN 1814-2079 online

http://www.informaworld.com 
hydraulic parameters, and bed-load transport relations. To integrate the modelled bed morphology into a numerical model, a reference point was established. The model was tested successfully with flume data in numerical flow calculations.

\section{Experimental investigation}

\subsection{Laboratory flume and test parameters}

The tests were conducted in a rectangular prismatic glass-sided flume $40 \mathrm{~m}$ long, $2.00 \mathrm{~m}$ wide and $1.20 \mathrm{~m}$ deep. The flume was subdivided longitudinally into two separate channels. The first channel, $20 \mathrm{~m}$ long and $1.50 \mathrm{~m}$ wide, represents the test facility with the mobile bed. The second one, $0.47 \mathrm{~m}$ wide, constitutes a lateral channel for the evacuation of the diverted discharge (Fig. 1).

The initial bottom slope $S_{o}$ varied between $0.1 \%$ and $0.4 \%$. The upstream (subscript 1) discharge $Q_{1}$ comprised a range of $0.098-0.222 \mathrm{~m}^{3} / \mathrm{s}$. The initial crest height $w_{D}$ of the side weir (subscript $D$ ) was fixed to $0.10 \mathrm{~m}$. Three weir crest lengths $L_{D}$ were tested, namely $3.00 \mathrm{~m}$ (test series B), $6.00 \mathrm{~m}$ (test series C) and two times $2.50 \mathrm{~m}(=5.00 \mathrm{~m})$ (test series D). As a reference case, tests without a side weir were performed (test series A). A detailed description is given by Rosier (2007b).

The side weir was located on the right channel bank $5.00 \mathrm{~m}$ or 40 approach flow depths from the main-channel inlet (test series B). For test series $\mathrm{C}$ and $\mathrm{D}$, the position of the side overflow was $3.50 \mathrm{~m}$ or 32 flow depths and 26 flow depths, respectively, downstream from the main-channel inlet. The weir crest was horizontal and rectangular with a crest width of $0.025 \mathrm{~m}$.

The bed material used in all tests consisted of sand of median diameter $d_{50}=0.72 \mathrm{~mm}$, a geometric sorting coefficient of $\sigma_{g}=$ 2.95 , density of $\rho_{s}=2,650 \mathrm{~kg} / \mathrm{m}^{3}$ and a bulk density of $\rho_{s}=$ $1447 \mathrm{~kg} / \mathrm{m}^{3}$ for a porosity of $p=45.4 \%$. The properties of the bed material are typical for the Rhone River in Switzerland.

For each test, the flow depth was recorded continuously in the centre line of the main channel using 15 Ultrasonic Gauges (US) (Fig. 1). The accuracy of flow-level measurement was $\pm 0.5 \mathrm{~mm}$.

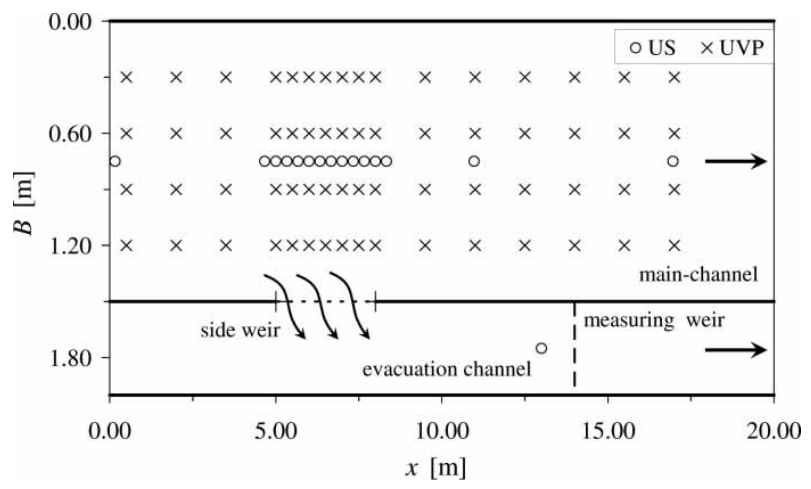

Figure 1 Plan view of laboratory setup for test series B with $3.00 \mathrm{~m}$ long side weir and arrangement of water level (US) and velocity (UVP) recordings
The 2D velocity field was measured with an ultrasonic-Doppler velocity profiler (UVP), allowing a $2 \mathrm{D}$ velocity profile over the entire flow depth to be obtained instantaneously (Metflow 2000). The probes had an emitting frequency of $2 \mathrm{MHz}$. Velocity profiles were recorded each $30 \mathrm{~min}$ for 16 cross-sections (Fig. 1). The final bed topography was recorded using digital photogrammetry (Rosier et al. 2004). For the digital elevation model (DEM), a grid resolution of $2.5 \mathrm{~cm} \times 2.5 \mathrm{~cm}$ as proposed by Wormleaton et al. (2004) was used. The vertical DEM accuracy is $\pm 2.5 \mathrm{~mm}$ which corresponds to about $3.5 d_{50}$.

\subsection{Measuring procedure}

The initial slope of the mobile flat bed for each test was created by adjusting the sediment layer to the desired slope. A coarser sediment layer was inserted at the channel inlet slightly upstream of the actual test reach to prevent erosion. A tilting gate at the channel exit facility was raised before slowly filling the main channel with water. Thus, the main channel and the evacuation channel were carefully filled with water until the horizontal side weir crest was reached. Then, the water level and velocity recordings were started. At this stage, the reference level for the water level measurements, corresponding to the side weir crest height, was determined. Next, the tilting gate was completely lowered and the discharge was increased to that requested, being constant throughout the entire test duration. The overall flow regime was always subcritical. However, local flow conditions could considerably differ from the average, and a large variation of Froude numbers may thus appear in a crosssection. Consequently, Froude numbers close to critical, at least numerically, were observed near the upstream weir corner where the flow is attracted by the weir.

Sediment was added $5.00 \mathrm{~m}$ upstream of the actual test reach via a conveyer belt. The quantities were estimated according to the formula of Smart and Jäggi (1983) and adjusted during each test to maintain uniform flow and equilibrium transport conditions in the approach flow channel. The sediment transport occurred primarily as bed-load or saltation as indicated by a mean value of $w / u^{*}=1.53$, where $w$ is sediment fall velocity and $u^{*}$ bed shear velocity (Raudkivi 1990).

The tests were run until the final bed morphology near the side weir was formed and a dynamic equilibrium was obtained. This was indicated by an almost constant spill discharge for a certain time period, usually occurring after about $25 \%$ of the total test duration (Fig. 2). A stable average side spill discharge was also a sign that the aggradation and the local sediment deposit were close to equilibrium. The test duration corresponds to the peak period of a flood event as may occur on the Rhone River.

The side overflow discharge was determined using a sharpcrested weir located in the evacuation channel (Fig. 1) and equipped with an ultrasonic gauge. The lateral overflow was never submerged from downstream and free overfall conditions were always ensured. 


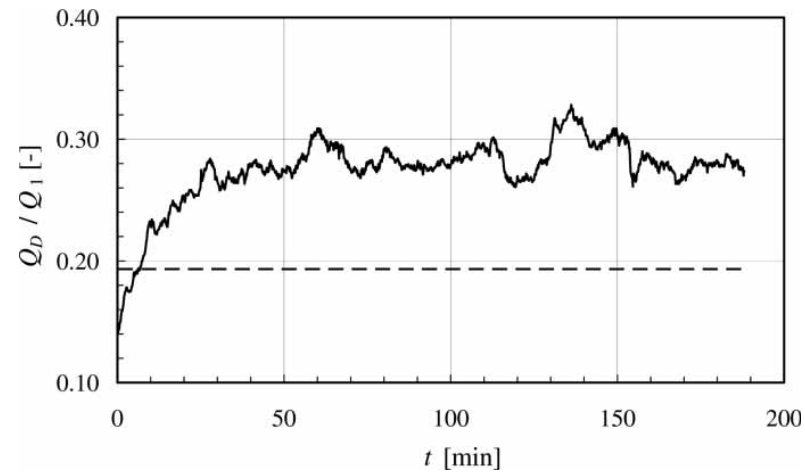

Figure 2 Transient evolution of diverted to approach discharge $Q_{D} / Q_{1}$ for Test B02. Due to passage of bed forms an oscillatory curve resulted. (- - ) $Q_{D} / Q_{1}$ ratio for plane fixed bed

\section{Parametrical description of local sediment deposit}

The systematic analysis of all tests revealed that the 3D shape of the deposit can be described by two longitudinal bed surface profiles on the left and on the right channel bank (Rosier 2007a). The profile on the right bank (subscript $R B$ ) represents the overall aggradation in the weir reach and the formation of a local sedimentary deposit forming at the downstream weir corner. The profile along the left bank (subscript $L B$ ) results only from the overall bed elevation in the side weir reach. The points of maximum (subscript max) elevation of the two profiles $\left(z_{\max , R B}\right.$, $\left.z_{\max , L B}\right)$ are characterized by a longitudinal displacement $\Delta x^{*}$ or angle $\phi^{*}$. The two profiles were connected as shown in Fig. 3.

To parameterize the two profiles, a Maxwell-type distribution function was used. The input parameters are expressed in terms of dimensionless relationships using relevant variables from the following four groups of parameters:

- main-channel geometry,

- side weir geometry,

- flow and

- sediment transport.

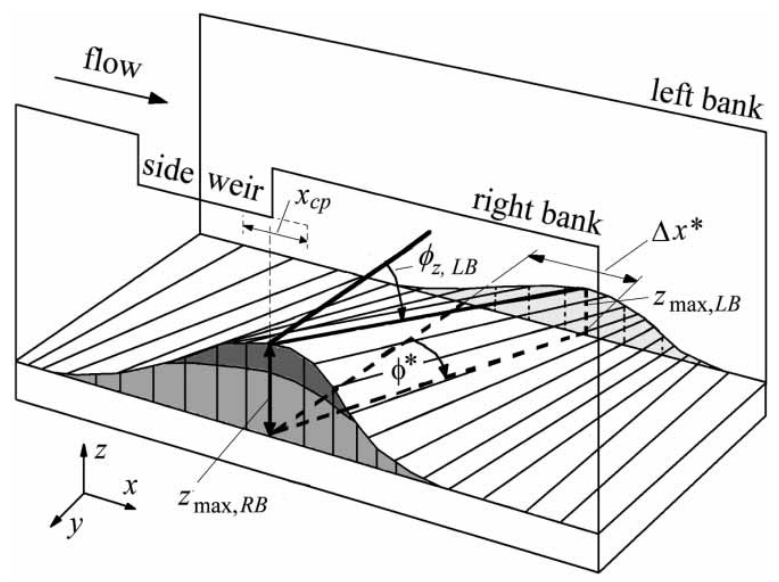

Figure 3 Schematic overview of parametrical description of sediment deposit. Variables and subscripts are defined in the text. The angle $\phi_{z, L B}$ represents the transverse inclination of deposit crest
To implement the bed evolution model into a numerical model, the location $x_{c p}$ of the modelled deposit relative to the side weir has to be known (Fig. 3).

\section{Development of semi-empirical model}

\subsection{Longitudinal bed evolution}

To determine the longitudinal bed profile along the right channel bank, the spanwise distribution of the maximum bed elevation along the side weir was analysed. The maximum bed elevation was within $y / B=0.85$ to 1.00 with $y=$ coordinate along the channel width and $B=$ channel width, corresponding to $0.15 B$. The same band width was also selected for the left bank, hence $y / B=0.00$ to 0.15 .

To detect the overall trend of the longitudinal bed surface profiles, bed forms had to be eliminated from each individual data set with the prerequisite that the bed discontinuity in the weir vicinity was not to be dampened. Therefore, a moving average procedure with a window length of $3.50 \mathrm{~m}$ was applied. Typical profiles are shown in Fig. 4. The deposit on the right bank is considerably larger than that on the opposite channel bank. Moreover, the longitudinal shift of the two profiles is apparent.

\subsection{Maxwell distribution function}

The main parameters characterizing the deposit are the maximum bed elevation $z^{*}{ }_{\max }$, the corresponding position of the maximum bed elevation $x_{\text {max }}^{*}$ its shape $n^{*}$ and volume. The deposit is skewed to the left with a rather steep stoss slope and a milder lee slope. Such a deposit shape can be parameterized with the Maxwell distribution function. The Maxwell-Boltzmann probability distribution has applications in physics and chemistry, e.g. heat and gas transfer, as well as in hydrology to describe the shape of flood hydrographs. The function is composed of only three dimensionless variables allowing for a continuous analytical solution. A further advantage, when compared with

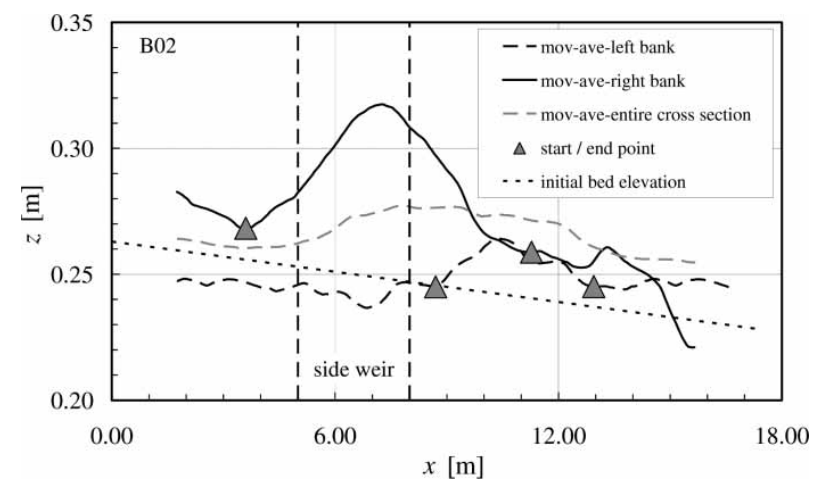

Figure 4 Bed evolution (moving average) in band width of $0.15 B$ along left and right channel bank for Test B02. Moving average of bed elevation over entire cross-section is also shown. Starting and end points correspond to Maxwellian analysis (see below) 
the Gaussian distribution, for example, is that it is bounded. Therefore, the Maxwell distribution function was used to fit the test data.

Introducing the dimensionless parameters $X=x^{*} / x^{*}{ }_{\text {max }}$ and $Z=z^{*} / z^{*}{ }_{\text {max }}$ with $x^{*}{ }_{\text {max }}$ and $z^{*}{ }_{\text {max }}$ as peak values of the bed elevation and the shape factor $n^{*}$ of the deposit, the aggraded channel reach near the side weir can be described by

$$
Z(X)=\left(X e^{1-X}\right)^{n *}
$$

By definition, the maxima of $X$ and $Z$ are located at 1.00 . For increasing $n^{*}$-values, the deposit shape becomes more peaked, whereas for decreasing $n^{*}$-values the deposit is wider and left skewed.

\subsection{Modelling with the Maxwell distribution function}

As a first step, the longitudinal deposit profile on the band of the right and left banks was defined. The starting and end points of the deposit were identified using a local minima analysis. For the starting point, the local minimum was defined by the distinct slope change from the upstream reach towards the maximum deposit elevation. The endpoint was determined by the same procedure (Fig. 5a). This process required a certain degree of interpretation, especially on the left channel bank where the deposit was far less prominent than on the right bank close to the weir. However, the deposit shape has a much smaller effect on the diverted flow over the weir than its height.

Once the two local minima were identified, they were linked with a linear function corresponding to the tangent in the respective points (Fig. 5a). The tangent was then used as baseline to extract the deposit from the original data set by vertical differencing (Fig. 5b). Next, $z^{*}{ }_{\text {max }}$ of the extracted deposit and its corresponding position $x^{*}{ }_{\text {max }}$ were determined. The Maxwell distribution function was then fit (Fig. 5c). The shape factor $n^{*}$ was found by a trial-and-error procedure using the least squares method.

\subsection{Maximum height of extracted deposit on right channel bank}

Channel, weir geometry, flow and sediment transport variables were included to determine the maximum height of the extracted deposit on the right channel bank $\left(z^{*}{ }_{\max , R B}\right)$ (Fig. 5b). The first three variables are represented by the ratio of overflow to approach discharges $Q_{D} / Q_{1}$. The overflow discharge is given by the general weir equation, whereas the open-channel flow is expressed with the Manning equation as

$$
\frac{Q_{D}}{Q_{1}}=\frac{(2 / 3) C_{D} \sqrt{2 g}\left(h_{1}-w_{D}\right)^{3 / 2} L_{D}}{R_{h, 1}^{2 / 3} n^{-1} S_{o}^{1 / 2} B h_{1}},
$$
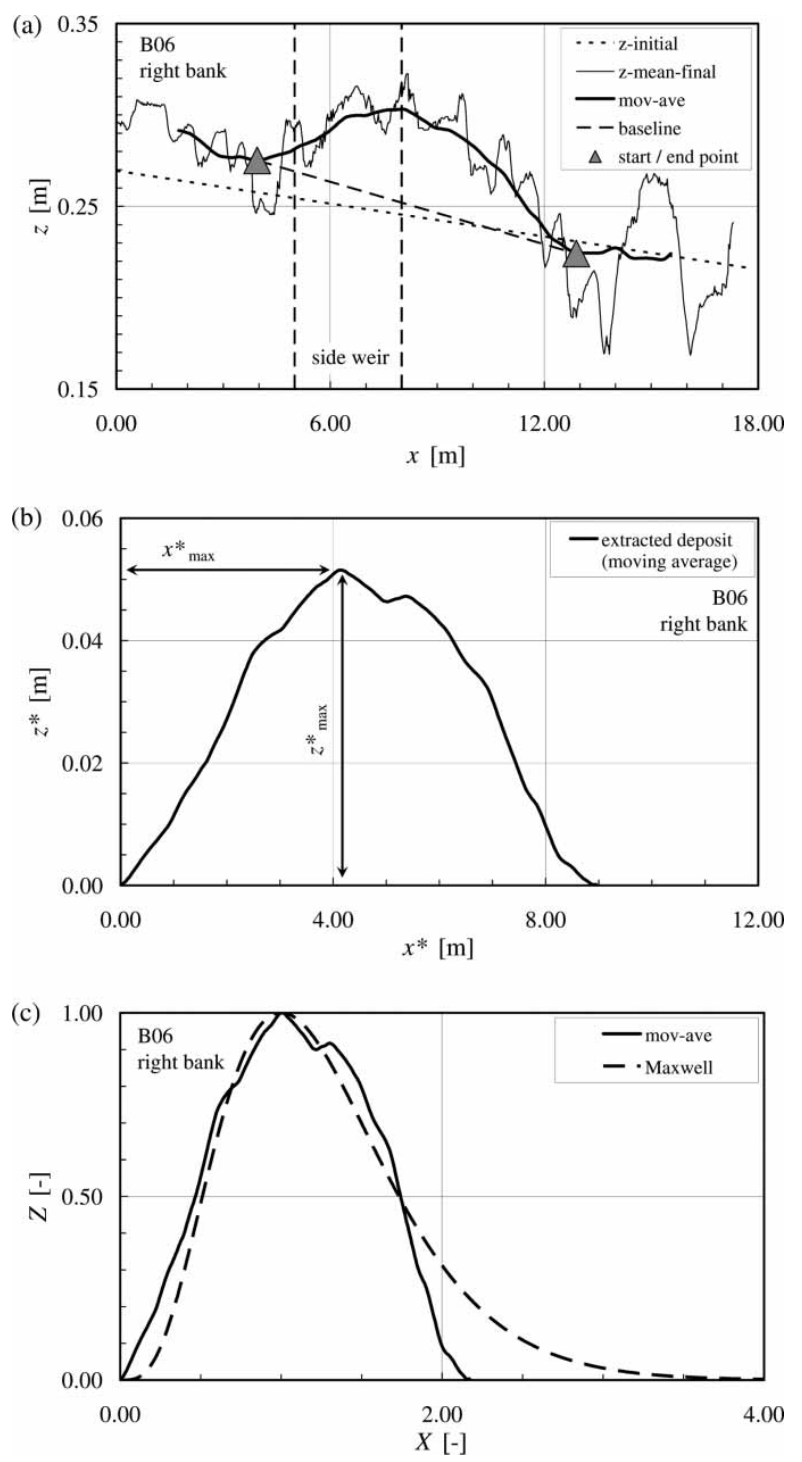

Figure 5 Example for deposit shape modelling by the Maxwell distribution function from original data set (Test B06, right channel bank, $0.15 B$ band width). (a) Initial mobile bed, average final bed, moving average for average final bed, start and end deposit points and baseline connecting start and end points (local minima), (b) extracted deposit, (c) normalized deposit and the corresponding Maxwell distribution function

where $C_{D}$ is the side weir discharge coefficient, $g$ the acceleration due to gravity, $h_{1}-w_{D}=h_{D, 1}$ the overflow depth above side weir crest, $h_{1}$ the approach flow depth, $w_{D}$ the weir height, $L_{D}$ the weir crest length, $n$ the Manning roughness coefficient including form roughness, $R_{h, 1}$ the hydraulic radius $\left(R_{h, 1} \approx h_{1}\right.$ for $\left.B / h_{1}>10\right)$ and $S_{o}$ the bottom slope and subscript 1 refers to the cross-section at the upstream weir corner.

A modified channel geometry as created by a lateral constriction or a negative bottom slope favours the establishment of pseudo-uniform flow conditions (Hager and Volkart 1986). Since the deposit induces a similar effect, the slight drawdown of the water surface profile is damped and the flow depth $h_{1}$ in Eq. (2) represents a rather suitable approximation for the normal flow depth. 
The effect of sediment transport was considered by the ratio of the downstream to upstream Einstein factor $\Delta \Phi$

$$
\Delta \Phi=\frac{\Phi_{\text {downstream }}}{\Phi_{\text {upstream }}} \quad \text { where } \quad \Phi=\frac{q_{s b}}{\sqrt{(s-1) g d^{3}}},
$$

with $q_{\mathrm{sb}}$ the bed-load transport per unit width, $s$ the relative density and $d$ the characteristic grain diameter. Typical $\Delta \Phi$ ratios varied between 0.39 and 0.94 with a mean value of 0.75 , indicating that during side weir operation about $25 \%$ of the approach flow bed-load material was captured in the deposit.

To express $z^{*}{ }_{\max , R B}$ non-dimensionally, the side weir pressure head $h_{D, 1}$ was chosen as $h_{D, 1} / z^{*}{ }_{\max , R B}$. Introducing the parameters $Q_{D} / Q_{1}$ and $\Delta \Phi$ to the genetic program GPKernel (Keijzer and Babovic 1999), various relations in the form $h_{D, 1} /$ $z^{*}{ }_{\max , R B}=\mathrm{f}\left(Q_{D} / Q_{1}, \Delta \Phi\right)$ were obtained. Based on the physical meaning, the degree of correlation and after regrouping and omission of terms of minor influence resulted for $0.75 \leq h_{D, 1} /$ $z_{\max , R B} \leq 10.50$ in

$$
\frac{h_{D, 1}}{z_{\max , R B}^{*}}=2 / 3\left[\frac{\Delta \Phi}{Q_{D} / Q_{1}}\left(3 \Delta \Phi-\frac{9}{5}\right)+\frac{9}{4}\right]^{4 / 5} .
$$

The application ranges are $0.04 \leq Q_{\mathrm{D}} / Q_{1} \leq 0.37$ and $0.39 \leq$ $\Delta \Phi \leq 0.94$. Since the ratios $Q_{D} / Q_{1}$ and $\Delta \Phi$ are a priori unknown, Eq. (4) has to be solved by iteration.

\subsection{Maximum height of extracted deposit on left channel bank}

The maximum height of the extracted deposit on the left bank $z^{*}{ }_{\max , L B}$ is obtained by introducing the angle tan $\phi_{z, L B}$ describing the transverse inclination of the deposit crest (Fig. 6; see also Fig. 3). The angle is supposed to be a function of the product

$$
\tan \phi_{z, L B}=\frac{\Delta z_{R B-L B}}{B}=f\left(x_{i}\right)=f\left(x_{1}^{\alpha} x_{2}^{\beta} x_{3}^{\gamma}\right),
$$

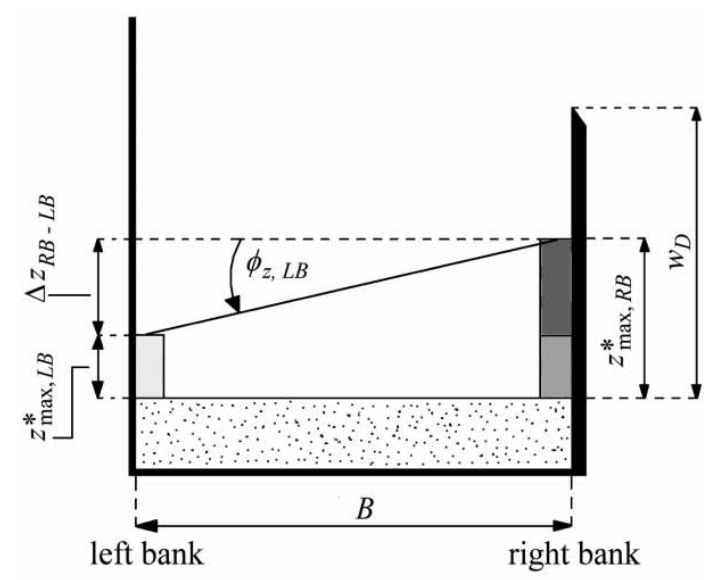

Figure 6 Definition sketch for angle tan $\phi_{z, L B}$ relating the maximum heights of the extracted deposits on right and left channel banks

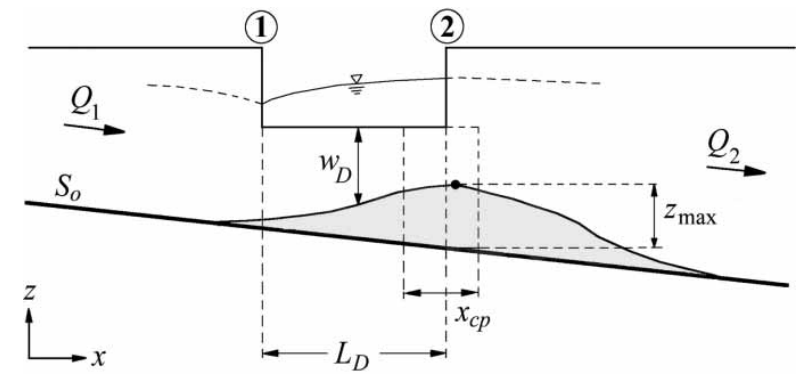

Figure 7 Definition sketch to implement aggradation model into numerical program. Location $x_{c p}$ of the maximum deposit height relative to weir refers to downstream weir corner (2)

with $x_{i}(i=1-3)$

$$
x_{1}^{\alpha}=\frac{Q_{D}}{Q_{1}}, \quad x_{2}^{\beta}=\frac{L_{D}}{B} \quad \text { and } \quad x_{3}^{\gamma}=\frac{h_{D, 1}}{L_{D}} .
$$

The exponents were determined to $\alpha=-2 / 3, \beta=1 / 3$ and $\gamma=$ $8 / 5$. The best correlation relating $\tan \phi_{\mathrm{z}, L B}$ to $x_{i}$ was found as

$$
\tan \phi_{z, L B}=\frac{\Delta z_{R B-L B}}{B}=a x_{i}^{b}
$$

Curve fitting indicated $a=11.16$ and $b \cong 1$. Consequently, $\tan \phi_{z, L B}$ is expressed by the linear relation

$$
\tan \phi_{z, L B}=11.16\left[\left(\frac{Q_{D}}{Q_{1}}\right)^{-2 / 3}\left(\frac{L_{D}}{B}\right)^{1 / 3}\left(\frac{h_{D, 1}}{L_{D}}\right)^{8 / 5}\right] .
$$

The difference between $z^{*}{ }_{\max , R B}$ and $\Delta z_{R B-L B}$ yields $z^{*}{ }_{\max , L B}$ (Fig. 6). The application range is $0.011 \leq \tan \phi_{z, L B} \leq 0.042$, $0.04 \leq Q_{D} / Q_{1} \leq 0.37,2 \leq L_{D} / B \leq 4$ and $0.004 \leq h_{D, 1} / L_{D} \leq$ 0.016 . The term $Q_{D} / Q_{1}$ has to be solved by iteration, since $Q_{\mathrm{D}}$ is a priori unknown.

\subsection{Location of maximum heights of the extracted deposits}

To find a non-dimensional relationship for the location of the maximum deposit heights on the two channel sides, the approach flow depth $h_{1}$ was used. The analysis indicated that for all tests $x^{*}{ }_{\max , L B} / h_{1}=21$ and $x^{*}{ }_{\max , R B} / h_{1}=30$ with ratios in the range of $12 \leq x^{*}{ }_{\max , L B} / h_{1} \leq 31$ and $23 \leq x^{*}{ }_{\max , R B} / h_{1} \leq 39$.

\subsection{Shape factors of the extracted deposits}

Since the deposit shape on the right bank varied insignificantly with the test boundary conditions, a constant value of $n^{*}{ }_{R B}=$ 5.52 was assumed. The analysis further indicated that the ratio $n^{*}{ }_{L B} / n^{*}{ }_{R B}$ is related to the ratio of side weir crest length $L_{D}$ and channel width $B$ as

$$
\frac{n_{L B}^{*}}{n_{R B}^{*}}=\frac{1}{8} \frac{L_{D}}{B}+\frac{2}{7} .
$$

The application range is $0.47 \leq n^{*}{ }_{L B} / n^{*}{ }_{R B} \leq 0.89$ and $2 \leq L_{D} /$ $B \leq 4$. 


\subsection{Longitudinal shift of extracted deposits}

To consider the longitudinal shift $\Delta x^{*}$ of the two profiles (Figs 3 and 4), the channel geometry and the flow regime were assumed to be adequately expressed by the approach flow Froude number $\mathrm{F}_{1}=v_{1} /\left(g h_{1}\right)^{0.5}$ where $v_{1}$ is flow velocity. Effects related to sediment transport and weir geometry are incorporated in the shear velocity $u^{*}{ }_{1}$ and the weir crest length $L_{D}$. As a result, the longitudinal displacement of the two profiles is given by the second order polynomial

$$
\begin{gathered}
\frac{\Delta x^{*}}{L_{D}}=23.26 x^{2}-0.11 x \\
x=\left(1-\frac{3 \mathrm{~F}_{1}^{2}}{2+\mathrm{F}_{1}^{2}}\right)^{1 / 2}\left(\frac{u_{1}^{*}}{\sqrt{g L_{D}}}\right)^{1 / 4} .
\end{gathered}
$$

The second term in Eq. (11) has the form of a Froude number. Its influence is small when compared with the first term, as indicated by the exponents. For $F_{1}=0$, i.e. $u^{*}{ }_{1}=0 \mathrm{~m} / \mathrm{s}$, the displacement is zero. For $F_{1}=1$, the first term in Eq. (11) tends to zero. Consequently, the application range is limited to $0 \leq \mathrm{F}_{1} \leq 1$.

\subsection{Location of the extracted deposit relative to side weir}

The downstream weir corner represents an appropriate coupling point to implement the modelled deposit into a numerical program (Fig. 7). Using the weir crest length $L_{D}$ for normalization, the location $x_{c p}$ of the maximum height of the empirical deposit around the downstream weir edge varied in all tests in the rather narrow range of $-0.34 \leq x_{c p} / L_{D} \leq 0.12$. On average, the coupling point is located at $x_{c p} / L_{D}=-0.13$, thus slightly upstream of the downstream weir corner.

For practical purposes, the maximum deposit elevation occurs at the downstream weir corner. There, the disturbance of the equilibrium between bed-load transport capacity of the main channel and sediment supply reaches its maximum. This location can be considered to be conservative, since the side overflow discharge $Q_{D}$ is larger than for a deposit located upstream of the downstream weir corner (Rosier et al. 2009a).

\section{Application of semi-empirical model}

To apply the bed elevation model in a numerical model, arbitrary boundary conditions in the test range were used as $B=1.50 \mathrm{~m}$, $S_{o}=0.001, L_{D}=3.00 \mathrm{~m}, w_{D}=0.10 \mathrm{~m}, Q_{1}=0.131 \mathrm{~m}^{3} / \mathrm{s}, Q_{D}$ $=0.022 \mathrm{~m}^{3} / \mathrm{s}, h_{1}=0.130 \mathrm{~m}, h_{D, 1}=0.026 \mathrm{~m}, \mathrm{~F}_{1}=0.60, u^{*}{ }_{1}=$ $0.036 \mathrm{~m} / \mathrm{s}$ and $\Delta \Phi=0.76$. In a first step, the normalized dimensionless deposit shape is determined (Fig. $5 \mathrm{c}$ ). The shape factor for the profile on the right bank is $n_{R B}^{*} \approx 5.52$. For the left bank Eq. (9) yields $n_{L B}^{*}=2.96$. With arbitrarily chosen increments on the left and right channel banks $0.00 \leq X \leq 4.00 \div 6.00$, the profile heights on the two sides result from Eq. (1).
Second, the shape of the extracted dimensional deposit is determined (Fig. 5b). With $x^{*}{ }_{\max , R B}=3.90 \mathrm{~m}$, the right bank abscissa $x^{*}=X x^{*}{ }_{\max , R B}$ is computed. The right bank ordinate $z^{*}=Z(X) z^{*}{ }_{\max , R B}$ is obtained by Eq. (4) with $z^{*}{ }_{\max , R B}=$ $0.05 \mathrm{~m}$. The abscissa and ordinate on the left bank are $x^{*}{ }_{\max , L B}$ $=2.73 \mathrm{~m}$ and $z^{*}{ }_{\max , L B}=0.015 \mathrm{~m}$ (Eq. 8). Herein, $\Delta z_{R B-L B}=$ $0.035 \mathrm{~m}$ (Eq. 7). The longitudinal shift of the left and right profiles is $\Delta x^{*}=3.054 \mathrm{~m}$ (Eqs 10 and 11). The shape and height of the two profiles as well as their longitudinal shift fully describe the 3D deposit surface.

The last step consists in implementing the modelled deposit in a flow calculation program. The location relative to the downstream weir corner is $-1.02 \mathrm{~m} \leq x_{c p} \leq 0.36 \mathrm{~m}$. With reasonable accuracy, the deposit can be placed directly at the downstream weir corner. If necessary, flow resistance due to bed forms has to be superimposed on the bed elevation model as well as that due to grain roughness (Kamphuis 1974, Ranga Raju and Soni 1976).

The prediction accuracy of the $3 \mathrm{D}$ semi-empirical model was tested for all experiments using the 1D numerical code HECRAS (version 3.1.2). On average, $91 \%$ of the measured overflow was predicted by the numerical computations within $86-94 \%$. The one-dimensionality of the numerical code and the selection of appropriate flow resistance are the main reasons for the differences. However, the overflow accuracy is better than for a $2 \mathrm{D}$-empirical bed elevation model, for which the accuracy is $85 \%$ (Rosier 2007b).

Since data from the test end with equilibrium conditions were used, the computed deposit shape corresponds to the final deposit shape of the tests. Usually, such information is not available and iterative computations starting with a flat bed have to be performed until a stable deposit and overflow discharge are obtained.

\section{Conclusions}

The interaction of a side overflow with a mobile channel bed was investigated experimentally. Owing to the lateral water loss, the sediment transport capacity in the main channel is significantly reduced within a short channel reach. As a consequence, sediment is deposited in the vicinity of the weir and the side overflow discharge increases in an unforeseen way. The analysis revealed that a short weir generates a more pronounced deposit and a higher side overflow than a longer, leading to a smoother deposit and a smaller overflow discharge. Based on systematic flume tests, a semi-empirical model to describe the 3D shape of the aggraded channel reach due to lateral water withdrawal has been developed. The main deposit properties, namely its maximum height, the location of maximum height and shape, were modelled using a Maxwell distribution function. The non-dimensional input parameters were expressed in terms of simple functions referring to channel and weir geometry, flow conditions and bed-load transport. The method provides good prediction and is simple to apply. 
The model application range is dictated by the ratio of crest length to channel width, the ratio of overflow to approach discharge, medium relative bed roughness, a mild bottom slope and subcritical flow regime. The model can be used to provide estimates of spilled discharge under steady flow conditions taking into account side weir-induced morphological bed changes.

\section{Acknowledgements}

The authors would like to express their gratitude to the Swiss Innovation Promotion Agency (CTI), Grant no. 4898.1, and to the Swiss Federal Office for the Environment (FOEN) for their sustained funding.

\section{Notation}

$B \quad=$ channel width

$C_{D} \quad=$ side weir discharge coefficient

$d=$ characteristic grain diameter, usually $d_{50}$

$d_{i} \quad=$ grain diameter for which $i \%$ of sediment is finer by weight

$\mathrm{F} \quad=$ flow Froude number

$g \quad=$ acceleration due to gravity

$h \quad=$ flow depth

$h_{D} \quad=$ side weir pressure head, flow depth above side weir crest

$L_{D} \quad=$ side weir crest length

$n \quad=$ Manning's resistance coefficient

$n_{D} \quad=$ number of side weirs

$n^{*} \quad=$ shape factor

$p \quad=$ porosity of sediment

$q_{s b} \quad=$ solid discharge (bed-load) per unit width

$Q \quad=$ discharge

$Q_{D} \quad=$ overflow discharge

$Q_{s b} \quad=$ solid discharge (bed-load) per unit weight

$R_{h} \quad=$ hydraulic radius

$s \quad=$ relative density

$S_{o} \quad=$ bed slope

$t=$ time

$u^{*} \quad=$ shear velocity

$v \quad=$ flow velocity

$w \quad=$ particle fall velocity

$w_{D} \quad=$ side weir crest height

$x$

$x_{c p}$

$x^{*}$

$X$

$y$

$=$ direction of rectilinear flow, channel distance

$=$ horizontal location of deposit relative to downstream weir corner

$=$ location of deposit height

$=$ dimensionless parameter in Maxwell distribution function

$=$ direction horizontally perpendicular to $x$ (transverse coordinate)

$=$ direction vertically perpendicular to $x$

$z^{*} \quad=$ deposit height of extracted deposit
$Z \quad=$ dimensionless parameter in Maxwell distribution function

$\Delta x^{*} \quad=$ longitudinal profile displacement

$\Delta z_{R B-L B}=$ difference between maximum height of profiles

$\Delta \Phi \quad=$ ratio of downstream to upstream bed-load discharge

$\rho_{s} \quad=$ density of sediment

$\sigma_{g} \quad==\left(d_{84} / d_{16}\right)^{1 / 2}$, geometric sorting coefficient

$\phi^{*} \quad=$ horizontal angle between location of maximum profile heights

$\phi_{z, L B}=$ vertical angle between the maximum profile heights

$\Phi=$ dimensionless intensity of bed-load discharge, Einstein factor

\section{Subscripts}

1,2 = beginning and end of side weir

$D \quad=$ relating to side weir

$L B, R B=$ left and right channel bank

$\max =$ maximum value

\section{References}

Borghei, S.M., Jalili, M.R., Ghodsian, M. (1999). Discharge coefficient for sharp-crested side weir in subcritical flow. J. Hydraulic Eng. 125(10), 1051-1056.

Hager, W.H. (1987). Lateral outflow over side weirs. J. Hydraulic Eng. 113(4), 491-504.

Hager, W.H., Volkart, P.U. (1986). Distribution channels. J. Hydraulic Eng. 112(10), 935-952.

Kamphuis, J.W. (1974). Determination of sand roughness for fixed beds. J. Hydraulic Res. 12(2), 193-203.

Keijzer, M., Babovic, V. (1999). Dimensionally aware genetic programming. Proc. Conf. Genetic and Evolutionary Computation, GECCO 2, W. Banzhaf, J. Daida, A.E. Eiben, M.H. Garzon, V. Honavar, M. Jakiela, R.E. Smith eds. Morgan Kaufmann Publishers, San Francisco CA, 1069-1076.

Metflow (2000). UVP monitor model UVP-XW: user's guide. Metflow SA, Lausanne, Switzerland.

Ranga Raju, K.G., Soni, J.P. (1976). Geometry of ripples and dunes in alluvial channels. J. Hydraulic Res. 14(3), 241-249.

Raudkivi, A.J. (1990). Loose boundary hydraulics. 3rd ed. Pergamon Press, New York, NY.

Rosier, B. (2007a). Bed evolution due to lateral water withdrawal. Proc. 32nd IAHR Congress, 788, G. Di Silvio, S. Lanzoni eds. Venice, Italy.

Rosier, B. (2007b). Interaction of a side weir overflow with bed-load transport and bed morphology in a channel. PhD Thesis, 3872, Ecole Polytechnique Fédérale de Lausanne EPFL, Lausanne, Switzerland. Also in Schleiss, A.J., ed. Communication 34, Laboratoire de Constructions Hydrauliques (LCH), EPFL, Lausanne, Switzerland.

Rosier, B., Boillat, J.-L., Schleiss, A.J. (2004). Mapping of bed morphology for lateral overflow using digital photogrammetry. Proc. 2nd Intl Conf. Scour and erosion, ICSE-2, Singapore, Singapore (CD-Rom). 
Rosier, B., Boillat, J.-L., Schleiss, A.J. (2009a). One-dimensional numerical modelling of mobile bed evolution in a flume with a side weir. Eng. Appl. Comp. Fluid Mech. 3(4), 487-498.

Rosier, B., Boillat, J-L., Schleiss, A.J. (2009b). Prediction of interaction between a side overflow and bed-load transport in a channel with semi-empirical approaches. Can. J. Civ. Eng. 36(11), 1755-1763.

Smart, G.M., Jäggi, M.N.R. (1983). Sedimenttransport in steilen Gerinnen - Sediment transport on steep slopes. Mitteilung,
64. Versuchsanstalt für Wasserbau, Hydrologie und Glaziologie (VAW). Eidgenössische Technische Hochschule Zürich (ETHZ), Zürich, Switzerland.

Subramanya, K., Awasthy, S.C. (1972). Spatially varied flow over side weirs. J. Hydraulics Div. ASCE. 98(HY1), 1-10.

Wormleaton, P.R., Sellin, R.H.J., Bryant, T., Loveless, J.H., Hey, R.D., Catmur, S.E. (2004). Flow structures in a twostage channel with a mobile bed. J. Hydraulic Res. 42(2), 145-162. 